\title{
Minority Employees Engaging with (Diversity) Management: An Analysis of Control, Agency, and Micro-Emancipation*
}

\section{Patrizia Zanoni and Maddy Janssens}

\section{Tilburg University and Katholieke Universiteit Leuven; Katholieke Universiteit Leuven}

ABSTRACT This study analyses how minority employees engage with control in organizations. Differently from most critical studies of diversity management, which focus on how minority employees are discursively controlled, we approach (diversity) management as a constellation of both identity-regulating discourses and bureaucratic controls. We assume that minority employees are agents who actively resist and/or comply with the constellation of controls they are subject to. Based on qualitative data collected in a technical drawing company and a hospital, the specific constellation of controls in each organization is first reconstructed. Four interviews with minority employees are then analysed in depth, showing how their engagement with material and discursive controls creates both constraints and possibilities of micro-emancipation.

\section{INTRODUGTION}

In recent years, diversity has increasingly been studied as an organizational discourse. Scholars in this domain have examined how the new discourse of diversity originated (Jones et al., 2000; Kelly and Dobbin, 1998; Liff, 1996; Liff and Wajcman, 1996; Maxwell et al., 2001; McDougall, 1996) and how it operates in organizations (Zanoni and Janssens, 2004), professions (Litvin, 2002) and broader institutional settings (Dandeker and Mason, 2001; de los Reyes, 2000; Martinsson, 2002; Wilson and Iles, 1999). Informed by a critical post-structuralist tradition, these discourse analytic studies make a major two-fold contribution to diversity research. First, they de-essentialize the notion of diversity by showing that demographic characteristics are not just given, but rather socially constructed. Second, they counter the rhetoric of diversity as a positive, empowering discourse stressing individuals' different capacities (Roosevelt Thomas, 1992) by illustrating how managerial discourses of diversity operate as control mechanisms. Specifically, they indicate that these discourses control by defining minority employees in

Address for reprints: Patrizia Zanoni, Tilburg University, Department of Organization Studies, Faculty of Social and Behavioural Sciences, PO Box 90153, 5000 LE Tilburg, The Netherlands (p.zanoni@uvt.nl). 
terms of fixed, essential group characteristics (Litvin, 1997) with negative connotations (Zanoni and Janssens, 2004), and by deploying such differences to reach institutional goals (Dickens, 1994).

Despite their unquestionable contribution to the theoretical development of a critical notion of diversity, these studies also present two major limitations. First, they tend to overlook the material structure in which discourses occur. Studies have focused on the intertextual linkages between diversity and a variety of other political and/or legal discourses of difference and equality (Dandeker and Mason, 2001; Kelly and Dobbin, 1998; Liff, 1996; Liff and Wajcman, 1996; Martinsson, 2002), economic discourses of efficiency (Litvin, 2002) and globalization (Jones et al., 2000; Kirby and Harter, 2001), and even biological diversity (Litvin, 1997), but have much less related diversity discourses to the material structure in which they are embedded. The few that do so (de los Reyes, 2000; Hagedorn-Rasmussen and Kamp, 2002; Maxwell et al., 2001; Wilson and Iles, 1999), present the material structure as introductory, background information, rather than analysing it in its dialectically constitutive relationship to the discursive structure (cf. Fairclough, 1998). Within such discourse-centred approach, control is reduced to its discursive dimension and more material forms of control remain unacknowledged. This stance is problematic because organizations never control employees solely through discourses, but always in multiple ways including material practices and structures (cf. Reed, 2000).

A second shortcoming of this body of literature is that it tends to fall into excessive determinism (Giddens, 1984; Newton, 1998; Reed, 2000) and to underplay minority employees' agency. It generally examines diversity discourses produced by powerful actors such as scholars, managers, legislators, and even religious leaders, as found in secondary sources such as books, mission statements, and legislative texts (Dandeker and Mason, 2001; Kelly and Dobbin, 1998; Litvin, 1997; Martinsson, 2002). The few studies that collect primary data largely focus on managers' or professionals' accounts of diversity (management) (Jones et al., 2000; Litvin, 2002; Zanoni and Janssens, 2004), rather than on accounts of the subjects who are defined by diversity discourses and who represent the primary target of diversity management. The focus on authoritative sources for the de-construction of diversity discourses leads to emphasizing their coherence and pervasiveness and to obscuring minority employees' role in reproducing or contesting them (Putnam and Cooren, 2004).

This neglect is particularly problematic in the light of recent critical theory on control which suggests that, in contemporary organizations, discursive control is largely mediated through the employee's self and not simply imposed upon it. In particular, it has been argued that: (i) managerial discourses operate as control mechanisms through identity regulation, a process whereby 'employees are enjoined to develop self-images and work orientations that are deemed congruent with managerially defined objectives' (Alvesson and Willmott, 2002, p. 619); and (ii) employees' engagement with managerial identity-regulating discourses does not merely operate as a control mechanism, but also potentially opens up opportunities for them to resist control and even micro-emancipate themselves (Alvesson and Willmott, 1996, 2002).

In this study, we address these two shortcomings to develop a more comprehensive and accurate understanding of how (diversity) management controls minority employees 
in organizations. We approach (diversity) management as a combination of controls embedded in an organization's mutually constitutive material and discursive structures. We further argue that minority employees are not passive receptacles of control but rather, as agents, reflect and act upon it in more or less compliant ways and that, through their reflections and actions, they can possibly create space for their own microemancipation. Our study also makes an empirical contribution to the critical management literature on control. While there are various critical accounts of how agents engage with organizational discourses (cf. Collinson, 2000, 2003; Kärreman and Alvesson, 2001; Sveningsson and Alvesson, 2003) and critical discourse analysis is explicitly concerned with how the discursive and the material intersect (Fairclough, 1998), there is still little empirical research on how subjects, as agents, engage with the material and the discursive structures that control them.

This study is based on qualitative material collected through semi-structured interviews in a technical drawing company, TechnoLine, and a hospital, Saint Mary (both are fictitious names). Within each organization, we interviewed managers, majority employees, and employees having a minority status in terms of gender, culture and/or (dis)ability. We analyse this material along three research questions: (1) How do the discursive and material structures of an organization jointly control minority employees? (2) How do minority employees, as agents, reflect and act upon these forms of control? and (3) To what extent are minority employees able to micro-emancipate themselves?

The paper is organized in five sections. First, to ground our research questions theoretically, we elaborate our perspective on control. We then describe our qualitative methodology including the data collection and analysis. In the third section, we present the distinctive material and discursive structures of the two organizations under study and show how minority employees are controlled. We then analyse in-depth four minority employees' accounts to understand how they engage with managerial controls. To conclude, we reflect on the contribution of this study to critical diversity research and, more broadly, to critical management studies.

\section{THEORETIGAL BAGKGROUND}

The theorization of control in organization has long oscillated between orientations focusing on the psychology of subjects and orientations stressing the role of the material structure in which work is carried out. Reacting to post-war industrial sociology's tendency to 'focus upon action and consciousness (e.g. orientations to work) while neglecting the structures which condition its expression' (Knights and Willmott, 1989, p. 537), Braverman (1974) argued in the mid-1970s that capitalistic control occurs through the material process of deskilling labour. More recently, under the influence of Foucauldian post-structuralist writing on the relationship between power and subjectivity and the growing body of literature on organizational culture (e.g. Kunda, 1992; Martin, 1992) and identity (e.g. Collinson, 1992; Kondo, 1990), there has been a renewed interest in 'softer' mechanisms of managerial control on employees. These mechanisms are argued to be more appropriate forms of control in post-Fordist organizations as they mobilize workers' discretionary commitment to the organization rather than their mere compliance with rules (Du Gay and Salaman, 1992; Thompson and Ackroyd, 1995). 


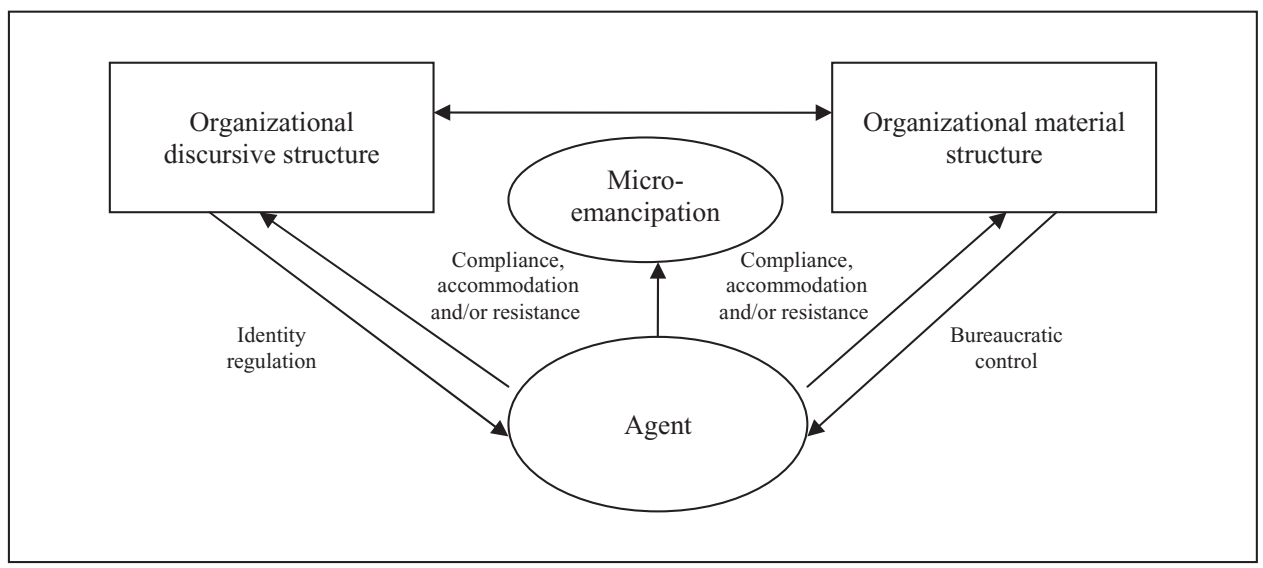

Figure 1. A theoretical perspective on control in organizations

In this study, acknowledging both the merits and limitations of these diverging views on control, we take a theoretical perspective that attempts to combine them dialectically. In our perspective, employees are controlled by a specific mix of bureaucratic and discursive controls originating in an organization's mutually constitutive material and discursive structures. We refer to these two interrelated modes of control respectively as bureaucratic control and identity regulation, and to their specific combination within an organization as a 'constellation of controls'. We further assume that employees are not mere receptacles of control but rather agents who actively engage with it (Collinson, 2000; Jermier et al., 1994; Prasad and Prasad, 2000) and who, through such engagement, might create opportunities for their micro-emancipation (Alvesson and Willmott, 1992, 2002). Our theoretical perspective is graphically presented in Figure 1.

In the following sections, we elaborate on the main concepts of identity regulation and bureaucratic control, discursive and material structures, and agency and microemancipation. Despite the complexity of our theoretical framework, we believe that each of these concepts is necessary to properly account for the multiple and ambiguous ways 'real' people (our interviewees) are controlled in 'real' settings (their organizations).

\section{Identity Regulation and Bureaucratic Control}

Identity regulation has recently been put forward as suitable concept to theorize control in contemporary organizations. The term refers to control which is 'accomplished through the self-positioning of employees within managerially inspired discourses about work and organization with which they become more or less identified and committed' (Alvesson and Willmott, 2002, p. 620), and therefore passes through employees' active development of identities aligned with managerial objectives. The incorporation of managerial discourses into narratives of self-identity occurs through several organizational processes, involving more or less purposeful 'identity work', through which subjects form, maintain, and repair their sense of who they are. For instance, espoused values and stories orient identity in a specific direction of who one should be, social 
events that regulate where one belongs, education programmes that present self-images of people, or status distinctions that express who is superior, equal or subordinate (Alvesson and Willmott, 2002). It has been argued that identity regulation represents a particularly powerful mechanism of control because it involves participation in organizational practices 'which are known or understood to provide the individual with a sense of security and belonging' (Collinson, 2003; Knights and Willmott, 1989, p. 550) in times of increasing job insecurity.

While identity regulation well explains how control is exerted by organizations via subjects' own 'identity work', it remains unclear how it relates to other forms of control in organizations. Recognizing that organizations increasingly exert control through identity regulation does not exclude that employees might be, at the same time, also controlled through, for instance, their position in the organizational hierarchy, bureaucratic rules, and surveillance technology. Such impersonal and bureaucratic practices of control might affect identity formation, yet they still primarily control by enforcing desirable behaviour.

To account for this variety in controls within contemporary organizations, we make an analytical distinction between identity regulation and bureaucratic control. The former refers to control that primarily operates through managerially inspired discourses and employees' own 'identity work', while the latter primarily operates by enforcing desirable behaviour through more impersonal, material, and stabilized practices (cf. below). As we explain in the next section, these two forms of control are embedded in the discursive and material structures of organizations.

\section{The Discursive and Material Structures}

In the context of this study, we define an organization's discursive structure as the set of interrelated discourses and the practices of their production, dissemination, and reception, which bring the organization into being (cf. Phillips and Hardy, 2002). In this sense, the discursive structure is key to understanding organizational control as it provides the discourses that can be deployed by management to regulate identities. It further stands in a mutually constitutive relationship to the material structure of the organization (Fairclough, 1998). In such relationship, the discursive structure (re)produces subject positions, social relationships and systems of knowledge and belief that constitute the material structure (Fairclough, 1998), while the material structure, in turn, provides the condition of possibility for certain discourses to emerge. Discourses always emerge in relation to what 'is already there, already in place' (Wetherell and Potter, 1992, p. 86, in Newton, 1998, p. 423), even if we acknowledge that 'reality' remains a matter of contestation and debate and nothing exists in a 'pre- or non-discursive arena' (Du Gay, 1996; Fairclough, 1998).

In our analysis, the material structure refers to power relations having a relative 'stability, deriving from repeated patterns in their social construction and reproduction over the medium to long term' (Newton, 1998, pp. 422-3, emphasis in original; cf. also Fairclough, 1998, p. 65). These power relations form a 'material' dimension of organizations in the sense that they are long-term and relatively undisputed, and, as a consequence, relatively undisputable by an individual. Similar to Bourdieu's (1990) doxa, they 
represent a (constructed) vision of 'reality' so naturalized that it represents the only 'reality' for all involved agents. These relatively stable power relations condition which discourses can emerge and how they are established (Newton, 1998; see also Fairclough, 1998).

In the context of this study, we operationalize the material as those power relations so consolidated that they are generally seen as 'facts'. For instance, we consider minority employees' lower position in the organizational ranks or their disadvantaged position in the wider labour market to be material. By doing so, we temporarily make abstraction of the discourses constituting that position. They are a fact in as far as all actors agree that minority employees hold less (higher) jobs than other employees, although they might disagree on the why's and how's. Typically, employers might discoursively construct this disadvantage by drawing from, for example, lack of skills, schooling, and right attitude, while minority employees might construct these positions as the result of racism and discrimination.

The material structure is important not only because it affects what types of discourses are established (and can possibly be deployed to regulate identity), but also because it operates itself as a mechanism of bureaucratic control. Stabilized constructions of power relations become embodied into and supported by organizational artefacts such as rules and routines, forcing employees to behave in certain ways. Minority employees' behaviours might be controlled in specific and particularly stringent ways, as an organization's material structure reflects and sustains the majority's power. For instance, to the extent that organizations follow the Western Christian calendar, they re-enact and reinforce a material structure that conflicts with non-Christian religious holidays, controlling religious minorities in a specific way.

\section{Agency and Micro-Emancipation}

In this section, we turn to the notion of agency and relate it to the concept of microemancipation. According to Giddens (1984), agency concerns an individual's ability 'to act otherwise', to intervene in the world or to refrain from such intervention, with the effect of influencing a specific process or state of affairs. In particular, agency refers to human beings' double capability to be reflexive about their situation - their 'discursive consciousness' - and to act upon it to 'make a difference'. It therefore entails the ability to exercise some sort of power, although agents are always and everywhere 'acting within historical specific bounds of the unacknowledged conditions and unintended consequences of their acts' (Giddens, 1982, p. 222). In this perspective, agency and structure are linked in the recursive process of structuration, whereby rules and resources (structure) both constrain and enable knowledgeable human agents' action producing social systems.

Giddens's understanding of agency is particularly suitable to our analysis because it allows us to highlight minority employees' engagement with various forms of control, through their reflection and action. Yet, at the same time, we attempt to avoid positing a pre-given unitary and sovereign subject, a common reproach to Giddens's perspective on agency (Newton, 1998, p. 418) and to remain faithful to a dialectic understanding of the agency-structure relationship. Through our empirical analysis, we hope to demonstrate that acknowledging that minority employees make a difference in their lives does 
not preclude adopting a non-essentialistic, historical conceptualization of subjectivity as constituted through a plurality of disciplinary mechanisms (cf. Knights and Willmott, 1989).

In line with this dialectic view, and with the idea that structure both constrains and enables action, we further draw attention to the possibility that, through their engagement with structure in the dialectics of control, agents can micro-emancipate themselves (Alvesson and Willmott, 1992, 2002). As managerial discourses and practices do not only control but also enable employees' reflexive action, they can facilitate resistance, and become potential means for their micro-emancipation. In this perspective, microemancipation is less grandiose and more focused than in orthodox Marxist conceptualizations. Rather, 'partial, temporal movements breaking away from diverse forms of oppression, rather than successive moves toward a predetermined state of liberation' (Alvesson and Willmott, 1992, p. 447) are emphasized. For instance, microemancipation might originate in a minority employee's increased control over his or her work arrangements, deriving from the flexibilization of organization in function of customers, or his or her enhanced status due to the official recognition of his or her specific skills to deal with clients belonging to the same socio-demographic group. In contrast to Alvesson and Willmott (1996, 2002), who relate micro-emancipation specifically to control through identity regulation, we extend the analysis to bureaucratic forms of control originating in the material structure of the organization. We believe that although identity regulation operates through the self and bureaucratic control is rather imposed upon it, minority employees, as agents, maintain in both cases the capacity to manoeuvre, engage with these controls, and sometimes open up spaces for their own micro-emancipation.

\section{METHODOLOGY}

\section{The Cases}

In this study, we analyse empirical material collected at TechnoLine, a technical drawing company, and Saint Mary, a hospital. These two case studies were selected out of a total of five conducted during the period 2001-02 as part of a qualitative, in-depth research project on diversity management in Flemish organizations commissioned by the Flemish government in Belgium. The five original organizations were known for their diverse workforce and their active diversity management. Following the logic of contrasting cases for theory generation (Eisenhardt, 1989; Yin, 1989), we selected the two organizations under analysis because of their distinct material and discursive organizational structure. They employ diverse personnel, in jobs requiring various types of skills, with different types of contact with clients/patients, and present more or less hierarchical organizational structures.

\section{Data Collection}

Within each organization, open-ended interviews were conducted with minority and majority employees at different hierarchical levels, the human resource manager, and 
line managers. In order to gain as broad a picture as possible of diversity and diversity practices in the organization, we selected respondents with different socio-demographic profiles and jobs (see Table I). Complementary information was collected through internal documents on the organizational mission, diversity policy, composition of the workforce, turnover, and absenteeism.

The interviews took place at the work place, were conducted in Dutch, lasted one to two hours, and were tape-recorded and fully transcribed. They were guided by a questionnaire of wide-ranging, open questions including topics such as the organization of work (What is your job? How is work organized?); the organizational culture (How would you describe this company's culture? How are the relations between employees and managers? How are the relations among colleagues?); the employment of minority employees (Why does the company hire minority employees? What jobs do they do?); the practices of managing diverse employees (What is your human resource management policy? What type of diversity related activities do you implement? How would you describe the relations between majority and minority employees?); and personal reac-

Table I. Interviews in the two organizations

\begin{tabular}{|c|c|c|c|c|}
\hline Interviews & Gender & Ethnicity & (Dis)Ability & Function \\
\hline \multicolumn{5}{|l|}{ Saint Mary's Hospital } \\
\hline Interview 1 (twice) & Female & Belgium & & Human resource manager \\
\hline Interview 2 & Male & Syria/Belgium & & Gynaecologist \\
\hline Interview 3 & Female & Belgium & & Head of cleaning \\
\hline Interview 4 & Male & Belgium & & $\begin{array}{l}\text { Trainer for health } \\
\text { assistants }\end{array}$ \\
\hline Interview 5 & Female & Belgium & & $\begin{array}{l}\text { Coach for low-educated } \\
\text { employees }\end{array}$ \\
\hline Interview 6 & Female & Belgium & & Head of nursing \\
\hline Interview 7 & Female & Belgium & Psychiatric patient & Cleaning staff \\
\hline Interview 8 & Male & Belgium & & Nursing staff \\
\hline Interview 9 & Female & Morocco & & Administrative staff \\
\hline Interview 10 & Female & Belgium & & Midwife \\
\hline Interview 11 & Female & Morocco & & Midwife \\
\hline Interview 12 & Male & Belgium & & Ombudsperson \\
\hline Interview 13 & Female & Belgium & & Head of nursing \\
\hline Interview 14 & Male & Hong Kong & & Cook \\
\hline \multicolumn{5}{|l|}{ TechnoLine } \\
\hline Interview 1 & Male & Belgium & & Manager \\
\hline Interview 2 & Female & Belgium & & Drawer \\
\hline Interview 3 & Female & Belgium & & Drawer \\
\hline Interview 4 & Male & Belgium & Disabled & Drawer \\
\hline Interview 5 & Male & Belgium & Disabled & Drawer \\
\hline Interview 6 & Male & Belgium & & Drawer \\
\hline Interview 7 & Male & Belgium & Disabled & Drawer \\
\hline Interview 8 & Male & Turkey & Disabled & Drawer \\
\hline Interview 9 & Female & Belgium & & Management staff \\
\hline Interview 10 & Female & Belgium & & Manager \\
\hline
\end{tabular}


tions and feelings towards the management and diversity practices (What is your experience of working in this company? What do you like here?).

We are aware that these texts, produced in interaction with an interviewer who was neither an organizational member nor a member of their same minority group, only offer glimpses of our interviewees' agentic behaviours. While the interviewer's status as a double outsider certainly affected the interview, it is difficult to assess how. The relative distance between interviewee and interviewer, together with the guarantee of anonymous and confidential handling of the information, might have created a relatively safe environment for the interviewees to speak frankly. On the other hand, we cannot exclude that they might have recounted their experiences in ways that they believed were more in line with a 'majority' interviewer's expectations. While translating and editing the excerpts, we did try to preserve their original meaning within the context of the whole interview.

\section{Data Analysis}

To understand how the organizations control their minority employees, each co-author separately coded all interview texts in terms of the material and discursive structure of the organization of work: nature of service, organizational structure, human resources policies and practices, managerial discourses, and its diversity management (reasons for hiring minority employees, vision on diversity, and diversity management practices). We then jointly reconstructed the cases and compared them. In a second stage, we selected two interviews with minority employees in each organization. As in the selection of the cases, the four accounts were not chosen for their representativeness, but rather because they better illustrated minority employees' engagement with managerial control. We first reconstructed the discursive and material structures each interviewee referred to, and then analysed how he or she reflected and acted upon constraints and possibilities, sometimes achieving forms of micro-emancipation.

\section{GONSTELLATIONS OF GONTROL ON MINORITY EMPLOYEES}

In this section, we introduce the two organizations under study and discuss their specific constellations of controls. We address our first research question of how minority employees are controlled by the discursive and material structure of an organization. For each organization, we first present the material and discursive structure and how such structure controls employees in general. We then discuss more specifically how the organizations manage minority employees, including their reasons for hiring them, and their visions on diversity and diversity management.

\section{TechnoLine}

TechnoLine is a technical drawing company founded in 1991. It designs machines and industrial installations and offers technical services such as CAD consultancy for product development. The company hired 'minority' technical drawers to cope with a deficit of skilled personnel in the late 1990s. They were formerly unemployed people that had received re-qualifying training by a public employment agency, WFD (Work For the 
Disabled). Some of them were from socio-demographic groups that have historically been underrepresented in qualified technical professions, such as women, the lower educated, the physically disabled, and people with a foreign cultural background.

TechnoLine is a flexible project-based organization with a strong client-orientation. Because most technical drawers work on projects at clients' premises, sometimes for several months, they are mainly directly supervised by the client they work for. Clients' expectations in terms of outputs, quality standards, timing, flexibility, and mobility further also shape TechnoLine's human resource management. For instance, a manager told us that 'training is identified depending on the client's needs and courses are held at the client's premises and scheduled to fit client's activities'. Clients further take part in employees' performance evaluations, the main ground on which promotion and salary increases are negotiated.

This material structure is sustained through an identity-regulatory managerial discourse that constructs employees as technically skilled, motivated, entrepreneurial, client-satisfying professionals. In the senior director's words: 'motivation, ambition, competences are ultimately needed to serve customers, as in the end, the client is king'. This discourse provides employees with a certain degree of autonomy and discretion while calling upon their sense of responsibility to perform in ways that satisfy the client and contribute to the attainment of organizational goals. As technical drawers have to work autonomously outside the organization, TechnoLine management mainly controls them through an identity-regulating professional discourse, which overlaps with and reinforces clients' bureaucratic control.

Within this constellation of controls, minority employees are constructed as individuals with professional skills, who are expected to perform as all other personnel members. The company does not have an autonomous diversity management, but rather manages them through its general, meritocratic (human resource) management. An employee's gender, formal schooling, (dis)ability and/or cultural background are in principle considered irrelevant: 'we just look at their work and what they are capable of, how eager to learn and how motivated they are' (senior director). The company does have a policy of addressing specific requests or problems on an individual ad hoc basis and always in collaboration with the clients involved. For instance, a female drawer told us: 'my current client agreed that I stay home on Wednesdays. But if I start working for another firm, I'll have to renegotiate this because not every client accepts such an arrangement'. Or a physically disabled drawer's mobility problems are discussed with the client, leading to flexible work arrangements allowing him to sometimes work at the office rather than at the client's site. This policy is however not cast as diversity policy and is in principle applicable to any employee. In sum, at TechnoLine, (minority) technical drawers are controlled through clients' surveillance and clients' involvement in most human resources activities in combination with the company's identity-regulating discourse of employees as empowered, client-satisfying professionals.

\section{Saint Mary's Hospital}

Our second case study is a medium-sized hospital located in a central urban area. Next to Flemish patients, the hospital has long been serving the local Jewish community and 
increasingly the growing Turkish and North African ones. Work at the hospital is organized hierarchically, following a strict division of labour reflecting rigid professional distinctions based on formal education. Saint Mary recently hired mostly young women with Turkish and Moroccan backgrounds to cope with a structural shortage of nursing and paramedic staff and with the increasing cultural diversity among patients. At the time of the study, a few nurses and midwives, one (male) doctor, some clerks, and several logistical assistants with different cultural backgrounds were working at the hospital.

Similar to all hospitals, the material structure of Saint Mary counts a variety of bureaucratic controls: rules (i.e. hierarchy, required qualifications, working schedules, procedures, quality standards, etc), surveillance technology (i.e. the time clock), as well as superiors' and patients' surveillance. Here, however, these multiple bureaucratic controls are complemented by a specific managerial discourse of openness towards employees and patients. As an organization with Catholic roots, 'the hospital wants to offer the best care in an atmosphere of warm humanity, respect and openness' (mission statement). At Saint Mary's Hospital, employees are controlled through the bureaucratic material structure typical of hospitals yet also subject to an identity-regulating discourse of members of a small organization providing care in a family atmosphere and in a socially and culturally sensitive way. This discourse 'softens' to some extent the rigid bureaucratic controls by providing employees with a positive professional identity stressing the human dimension of care.

The perspective on diversity revolves here around minority employees' specific linguistic and cultural skills, which are considered essential to ensure that minority patients receive appropriate medical care, as 'the hospital wants to adapt its policy to the needs and concerns of all and therefore also migrant patients' (ombudsperson). Minority employees are therefore expected to make a specific contribution to the health service by virtue of the background they share with patients. A doctor mentions some of the hospital's diversity initiatives: 'minority employees translate, when necessary, between doctors and patients, we have a wide selection of food for patients, and we place, whenever possible, patients with similar cultural backgrounds in the same room'. Moreover, a multicultural work group organizes activities including information sessions about rituals of birth and death in different cultures, intercultural communication trainings, visits to the Jewish and Turkish neighbourhoods, and a multicultural calendar with all religious holidays. An anti-discrimination clause has been included in the hospital's bylaws, and an ombudsperson handles all culture-related conflicts. Yet, at the same time, the hospital has a policy strictly forbidding employees to wear a scarf for hygienic reasons.

Within the material and discursive structure of the hospital, minority employees are controlled in partially specific ways. Like majority employees, they are controlled through the material organization of work allowing for superiors' and patients' surveillance as well as through the identity-regulating discourse of employees as open, culturesensitive, flexible carers. However, the managerial discourse of cultural diversity also provides them an additional, specific professional identity as 'cultural experts' for patients belonging to their same cultural group. Through this latter discourse, the hospital attempts to control minority employees by highlighting their specific cultural competences in a positive way, which further contributes to softening the impersonal bureaucratic controls imposed upon them as (minority) employees. 


\section{Conclusion}

In our two organizations, minority employees are controlled in clearly different ways. TechnoLine has no autonomous diversity management and controls minority employees through its general management, characterized by strongly overlapping and mutually reinforcing material and discursive structures. Clients supervise employees while the company regulates their identity as responsible empowered professionals. In contrast, Saint Mary's Hospital implements specific diversity initiatives and manages minority and majority employees in partially specific ways. Its material and discursive structures control employees in complementary ways: strict bureaucratic rules are partially softened by a general identity-regulatory discourse of employees as open, flexible carers, and a specific identity-regulating discourse of minority employees as cultural experts.

\section{MINORITY EMPLOYEES ENGAGING WITH MANAGERIAL CONTROL}

In this section, we address the second and third research questions and examine how minority employees reflect and act upon the control exerted over them, and to what extent are they able to micro-emancipate themselves. In order to maximize the space for interviewees' own voice, we provide extensive excerpts of four interviews with minority employees, two for each organization, and then interpret how they, as agents, engage with control, sometimes creating possibilities for forms of micro-emancipation.

\section{Ahmed, Technical Drawer at TechnoLine}

When I was 17, I dropped out of school, a difficult period . . My father wanted me to study but I was young and had had enough... Some teachers have extreme ideas ... As only [Moroccan] migrant in the class . . . they tell you: I'm going to flunk you this year ... that doesn't motivate . . Y You focus on your culture, even though it might not be the only issue ... Still, Belgium is not so ideal for a migrant . . .

I first worked as a welder but then I got asthma and eczema and had to stop . . . I stayed on sick leave benefits till I started at WFD [Work For the Disabled, public training agency for disabled unemployed people] . . . I passed the psychological tests and did a CAD training ... I did not even know what a computer was! . . I was motivated and finished fast . . . I had to do a one-year internship in a company, but I stopped after three months, the company did not suit me . . I am ambitious, I fight hard, I've learned that with time ...

I went back to the WFD but they didn't appreciate it, they thought that I was just after the money ... Anita [the director] told me that I was a 'moneywolf', trying to sell myself to the higher bidder. She said that they do not sell people, they place them, and that we should be happy that we can be back to work ...

In the end, I could sell myself to a technical consulting . . . It turned out well . . . I started as a drawer but could proof myself... I stayed there a year and a half . . . Then I worked at Siemens for two years. They asked me to stay but I refused, I had heard that the company was not going well . . . Then I went to Philips ... 
At TechnoLine I started at the bottom of the ladder . . But here they look at what you can do, your potential through your studies, your work experience . . I brought in a big partner, the number one selling software on our market . . Y You have to know how to prove yourself, to sell yourself, and you get respect, you become a 'respectable specialist', you have a higher status ...

Every year we have a big get-together ... It's always well taken care for, food, drinks, a good atmosphere. You meet your colleagues and get to know new people. It's up to you to make contact. If you let me do, in no time, I look for people and make them loosen up. It's in me, I can entertain.

John [the director of one of the branches of the company] believed in me ... I climbed up the ladder, which I couldn't do in other companies. If the client is satisfied with your work, you get a promotion. It's difficult sometimes, like everywhere . . But I am loyal to this company because I see chances here ... In other companies you need a degree, that piece of paper ...

I set my conditions: I'm no 'cheap bird', but it can get even better ... In the beginning, I told them that they could get subsidies for hiring me. I mentioned it only once, because I want them to value me for my work, not because I'm cheaper. It would really hurt me.

I do talk about my background. During Ramadan, I just switched my days and nights ... At the end of the month, I told John: 'Sorry, I had to do it'. And he answered: 'Have you heard me complain?' It was fantastic. Give me my freedom, and I'll make profit, but if you tell me do this and do that, I won't do it . . .

The only thing is that feeling of . . I can do more, climb higher, do sales . . But because of that, I've got five ulcers, my planning is completely full, even my free time.

An employer has to look for his money. Unfortunately, this does not happen everywhere: [as a minority] you have to be either three times as good or you are simply not hired... This is often the mentality about minorities, women ... Not here, though, here if you work the same [as other employees], you get paid the same. You work better, you get paid more. This is just economically right . . . John does a lot for his people ... He will take into account the limitations of a disabled drawer but for the rest he sees us all as 'racing horses', he expects the same motivation, work and performance from everybody.

In his interview, Ahmed mentions a variety of material controls such as the pervasive discrimination towards minorities, his weak position on the labour market due to lack of formal education, the western calendar and working hours, the flexible project structure of TechnoLine, clients' demands and standards, and the long working hours. At the same time, he refers to different identity-regulating discourses: negative discourses about migrants, the assistance discourse of the WFD, and TechnoLine's discourse of employees as competent, entrepreneurial, client-oriented professionals.

This specific constellation of controls at once closes and opens up possibilities for Ahmed. As an agent, he reflects on these constraints and possibilities and attempts to act in ways that minimize the former and maximize the latter. Ahmed's account is structured along the comparison between his negative past before entering TechnoLine and his current positive experience within this organization. In the past, he often faced discrimi- 
natory behaviour and related identity-regulating discourses constructing cultural minorities in negative terms. These experiences led Ahmed to quit his studies, a decision that compromised his whole future, as formal education is generally necessary to get a decent job and to advance professionally in many (big) organizations. However, another material constraint, his allergy, unexpectedly opened up a new chance for him to attend a training course at the WFD. He took this chance and made the best of it. His new qualifications improved his position on the labour market and boosted his selfconfidence, he stopped his internship in a company which in his eyes gave him no opportunities, countering the WFD's attempt to temper his ambition. Ahmed refuses to construct himself as a loser, challenging the agency's identity-regulating 'assistance discourse' which constructs the disabled simply as difficult-to-place individuals.

After working in a number of other organizations, Ahmed was hired by TechnoLine, which he portrays as the ideal environment for him to grow professionally. The specific constellation of controls in this company opens up serious career possibilities for him. The material project structure, requiring employees to work in autonomous ways, and the key role of clients, requiring excellent relational skills, match Ahmed's competences. The related identity-regulating discourse of employees as autonomous, entrepreneurial, and client-oriented provides him a positive professional identity for the first time in his career. He sees the empowering effects of meritocracy over (overt) discrimination and enthusiastically identifies with the organization's economic logic: the perfect market is fair, blind for race or disability, if one just competes.

Ahmed's compliance with the material and discursive controls at TechnoLine is however not complete. His endorsement of the organizational objectives and his performance enable him to adjust material working arrangements to practice his religion. Without consulting his superior beforehand, he switches days and nights during Ramadan to fast with the rest of the Muslim community. Clearly, in his case, professional success represents an important source of micro-emancipation, making it even possible to circumvent the material structure of the Christian calendar, around which Western societies are organized. By complying with TechnoLine's material and discursive controls, Ahmed builds an empowering identity and a stronger position on the labour market which allow him to negotiate work arrangements that better suit him.

Ahmed's experience is exemplary of why compliance with organizational goals might not only just be appealing to an individual but even represent a source of microemancipation. While Ahmed does not elaborate on the positive effects of his success beyond the professional context, considering the weak position of cultural minorities and his past, it is likely that thanks to it he now enjoys a much higher status within both his community and Belgian society as a whole. Ahmed's is a remarkably linear and coherent story of redemption from school dropout to successful professional, whereby he increasingly stresses his own role in shaping his future. Only on two occasions does Ahmed admit his vulnerability as an individual. In one passage he acknowledges the high price of his success: he has no free time and rather serious health problems. Second, he expresses his gratitude towards his boss, who has given him a chance and the freedom to organize his work as he wishes, revealing that he might not be completely in control after all. 


\section{Robert, Technical Drawer at TechnoLine}

I received my technical training at the WFD ... Then they contacted various companies. They always asked me what I thought about it. For me, it needed to be accessible by public transport. The WFD organized an interview at TechnoLine. They give the company your $\mathrm{CV}$, they take care that you get off the street... The WFD has been good to me and I think I got in right on time 'cause the market was getting more difficult for technical drawers. They had arranged everything.

But the WFD doesn't ask enough. If you go work they say: 'Don't expect too much ... it's not well paid'.

I had been 8 years on sick leave benefits when I started. My first wage was above the benefits, so I didn't discuss too much. The atmosphere is good here and I wanted to work ... I'm not a hard negotiator.

They don't tell us much. When there is a serious chance that you get a project, they tell you that you have to work for that client with that software ... I don't have a problem with that. If they can keep me busy, they don't have to tell me much in advance. That's their problem; it's not my job ...

I can't make promotion here. People that want to get higher have to go to clients. It's not for me ... I ask to stay at the office. There are clients which I can reach if I ride with a colleague. But if there are stairs there, then I have a problem. Last year I was on sick leave for two months. I had gone too often to a client's ... My leg got seriously inflamed. I want to avoid being on sick leave for so long again ... I liked being out of the office, but if this is the price, it's better I don't do it. I do go smoke a cigarette when my leg begins to hurt, 'cause I'm afraid it gets bad. I don't want to stay home. I get nuts. If they just paid me right, promotion wouldn't be an issue at all.

The boss thinks that I'm too slow, not only me ... They want to squeeze you like a lemon. Once they threw in my face that if you work eight hours, you have to sit in front of your computer eight hours ... I've been looking ... I heard about a law that if you work on the computer, you get five minutes break every one or two hours 'cause it's not healthy. I want to catch them with something that doesn't have to do with me personally, a general rule. If it's a law, they have to allow it. This is how I am ...

Actually they should get me a special chair. They know they can ask for one [subsidized] but they don't want to do the paperwork. I've told them that, if they don't even take the time for that, they'd better take I go smoke a cigarette more ...

I do think that my boss makes loss on me. Otherwise, he would put me on any project, on what pays best. . . But he has to keep me here at the office. It's more work for him and it's not easy for the client, either, 'cause he can't see me...

The employer gets 40 per cent of the total cost back. I can't always sit, I have to stretch my leg every now and then. But ... I'm never 40 per cent of my work time off the computer ... I do smoke but there are other smokers, not disabled, and for them they don't get any subsidy. We [the disabled] are considered less ...

Colleagues don't look down on me, except when it's about wages. Those who have a bachelor in engineering... But the atmosphere is very good here.

They can fire me if they want ... In principle I can't get here on my own ... I'm trying to get a [subsidized] taxi to take me here from the closest bus stop. An adapted 
car doesn't interest me, I live in town and they break everything . . But I would like to come on my own, instead of bothering colleagues . . .

I'm looking for work elsewhere ... You do see that they are prejudiced against disabled people. They are enthusiastic about your CV. I always mention that I walk on crutches. When I tell them that it's permanent, 80 per cent falls out. It's bad, but I can't do anything about it. I'm looking for a job in a production company. In consulting you always have to go to clients. I don't contact companies that are in old houses. They are on different floors and there is no lift.

In his interview with us, Robert mentions a variety of material controls he experiences at TechnoLine and on the wider labour market. As an employee, he is controlled by his employer's expectation that he works uninterruptedly. At the same time, as a physically disabled employee, he feels specifically controlled by the inaccessibility of the company by public transport, the office infrastructure, and the architectonic barriers that limit his mobility and flexibility to work with clients. As TechnoLine's core activities require intense, long-term contacts with clients, these constraints affect him in a particularly negative way. He cannot perform as other employees nor use clients' satisfaction to negotiate salary increases and adjusted working conditions that accommodate his personal needs. At the same time, Robert is controlled by the company's identity-regulating discourse of employees as competent, entrepreneurial, client-oriented professionals, in line with the material structure delineated above, and by the assistance discourse of the WFD attempting to temper disabled workers' professional expectations and claims.

Reflecting on the constellation of controls he is subject to from his specific position, Robert cannot identify possibilities of micro-emancipation and rather takes a clearly antagonistic stance vis-à-vis his employer. His impairment prevents him not only from performing as expected but also from developing a positive professional identity in line with organizational goals. Management even constructs him as lacking motivation, further instigating his resistance. Robert only minimally complies with the controls imposed upon him: he does arrange with his colleagues to get to work and does stress that he wants to keep working. However, he refuses to work harder than his able-bodied colleagues and to give up his cigarette breaks. As an agent, he constructs himself as subordinate employee with limited, strictly executing responsibilities against the desirable TechnoLine professional identity. He further draws on labour law to construct an antagonistic identity and come up for his rights. He denounces his employer for paying him below legal standards, not providing him an adequate working station, and profiting from state subsidies for the employment of the disabled.

In his account, Robert gives a particularly nuanced account of the dialectic between his own power as an individual (who happens to be physically impaired) and the material and discursive structures that control him. On the one hand, he stresses the multiple constraints deriving from the seriousness of his impairment, the numerous architectural and logistical barriers, and the project structure of TechnoLine. He further acknowledges the decisive role of the WFD's training and assistance in finding a job while also blaming it for failing to ask for proper work arrangements, and adequate compensation for the disabled. On the other, he points to the fact that he himself took the initiative to re-school, stresses that he absolutely wants to work and to avoid being on long-term sick 
leave again, and that he is looking for other (better paid) work. These elements make us speculate that, in spite of all difficulties, employment tout court might represent for Robert one of the few available sources of self-esteem and possibly micro-emancipation in Belgian society, where the disabled have long been cast as patients in need of assistance rather than as competent individuals. It is through his antagonistic identity and behaviour that Robert is able to conciliate his need to make a difference in his life (and possibly micro-emancipate himself) with the multiple material and discursive constraints he faces every day both inside and outside TechnoLine.

\section{Saida, Midwife at Saint Mary's Hospital}

I've been working here for three years, first as a nurse and now as a midwife. After my studies I couldn't find a job as a midwife, so I worked as a nurse . . There are too many midwives.

I had sent an application letter for a job here a couple of times. They wrote back that my name was in their database. After two years I heard that many young people had been hired, so I called. I came here and asked why I had not been contacted. So I could go for an interview and they hired me.

I'm the only one with a different cultural background. That has never been a problem. People know me from my internship. On the contrary, they said: 'A Moroccan, so you can translate ...' They were positive ... I feel very much at home here in comparison to other hospitals. I never got a racist remark from colleagues or patients. I also try not to focus on it, to let it go . . . I didn't during my internship and you end up thinking always about yourself, instead of working . . . I have to put it aside.

Midwifery is a woman's job. We don't have to wash men . . . In our religion women can wash men only when it's really necessary, like in war . . I chose to become a midwife because of my own interest... Parents are more open now and let their children choose . . . Midwifery is valued . . For instance, if you are in a shop and they hear you are a midwife, they treat you with more respect. It's 'cause the Prophet's mother was a midwife.

Most [Moroccan] women come here 'cause they say it's a good hospital. Even if they don't speak Dutch and their husband is not with them. They have the feeling that the staff want to help them. I find that in this hospital they have a natural vision over pregnancy and birth-giving. It's less technical than in other hospitals. Perhaps because of the mentality of the midwives, and the gynaecologists go along with it. It's an atmosphere ... We let people free to deal with labour as they wish, we don't push anything.

The midwife assists the woman during labour, while the gynaecologist arrives only when the baby is about to come. With a male midwife it would be more difficult, because you build a certain intimacy with the woman ... It could be a problem for migrant women.

My parents never put me under pressure to wear a scarf . . Like praying. After graduation I started reading and it came naturally. You ask yourself who you are, your identity, and everybody says: 'I am Muslim', but what does it mean? 
I've had mixed feelings about it [the prohibition for personnel to wear the headscarf in the hospital]. In our religion, it is often said that you have to keep your home situation and your work apart. So, I've had to accept it. I would like to wear the scarf all the time, 'cause you feel a 'double person' . . . But I've finally accepted it, I don't have a problem with it. The Islam doesn't say that you have to be extreme, extremism is wrong, in every religion. You have to go with the times and the situation.

I think that they would take Ramadan into account [when scheduling her work] if I asked. But they don't have to. Eating and then going back to work when your colleagues eat an hour later, it's just not feasible.

[About the hospital's diversity policy] It's not like in The Netherlands. There it's much more intense, they evaluate a lot, also together with migrant personnel. All decisions are taken by migrant staff . . . I think you have to involve the migrant staff in everything.

Nobody ever asked why I wear my headscarf [insinuating that she shouldn't] ... On the contrary, they are interested. If they don't understand, they should have somebody to ask to. They know I'm open about it. There are no stupid questions.

I have friendly neighbours that say: 'Sorry, but we vote VB [extreme right party]. We don't have anything against you ...' I have relatives that haven't been here for long ... I go with them to temporary work agencies, but they say: 'Sorry, we have employers that don't want Moroccans ...' I never had problems myself.

In her interview with us, Saida mentions a variety of material controls such as the hospital's hiring practices, working schedules, exclusion of minority employees from shaping the diversity policy, and policy forbidding the headscarf, as well as the difficult labour market for midwives and migrants and pervasive racism and discrimination in society at large. Moreover, she refers to a variety of identity-regulating discourses originating in the hospital, her professional community, the Moroccan community, and Belgian society at large: the hospital's discourse of 'open' and 'natural' health care, its diversity discourse centred around providing appropriate care for migrant communities, the professional discourse of patient-oriented (female) midwives that opposes them to more technically oriented (male) doctors, the Moroccan community's view on midwifery as an appropriate job for a woman, and Belgian society constructing Moroccans in negative terms.

For Saida, the combination of these various controls creates both constraints and possibilities. As an agent, she reflects and attempts to act in ways that make the best out of them. For instance, on the positive side, the hospital's culture-sensitive approach to patients and its 'natural' approach to care match the Moroccan vision on birth-giving, enabling Saida to build a positive professional identity as a midwife that is valued in both the hospital and the Moroccan community. Also, conscious of the bad position of minorities on the labour market as well as the related negative discourses on minorities, she stresses the positive sphere at Saint Mary's, where she feels more 'at home' than in any other hospital. Yet, at the same time, the hospital's prohibition to wear the scarf conflicts with her personal choice to do so (conform to her community's tradition), making her feel 'a double person'. Similarly, during Ramadan she does not ask for 
special treatment because it would interfere with general work arrangements and disrupt relations with colleagues. In these cases, she resolves conflicting demands from the hospital and her community of origin by complying with hospital rules. She however minimizes the conflict by constructing a moderate Islam and by waiting for the break to eat during Ramadan.

Saida does not always comply, however. Faced with the lack of jobs for midwives, she temporarily accepts to work as a nurse, but when she thinks that she is not being given a chance, she does push to get a job at the hospital. Also, drawing on the hospital discourse of diversity, which casts her as a cultural expert, she claims a bigger role for herself and other minority employees in defining and evaluating the diversity policy, resisting thus being relegated to mere execution. In other words, she exposes the contradiction between a discourse that values her specific competences and a managerial practice that excludes her from the decision-making process, and deploys the former to question the latter.

More subtly, Saida resists dominant negative discourses of Moroccans in Belgian society, constructing the Islam as a moderate, accommodating religion and Moroccan parents as open towards their children's preferences (including girls). In this way, she reduces potential conflicts between the Belgian majority and the (Muslim) Moroccan minority, discursively creating a legitimate place for herself and her community in Belgian society. She further supports her arguments by denouncing the widespread racism and discrimination, yet stressing that she never directly experienced it, avoiding to cast herself as a victim.

Throughout her interview, Saida presents herself above all as an individual who reflects on her specific situation and makes conscious personal and professional choices. She complies with control she feels she cannot challenge, but does take the initiative when she feels she can make a difference in her life. Despite the multiple forms of control she experiences, Saida's accent on her own ability to deal with various forms of control sets the interview in an overwhelming positive tone. While stressing her own agency might in part be functional to constructing a positive identity vis-à-vis us in the interview situation, the modalities of her account do indicate that she is able to successfully identify possibilities for her micro-emancipation. Saida complies with rules she cannot bend but also draws from the identity regulatory discourses on culturally appropriate, natural care to build a professional identity as a midwife that is empowering to her in various contexts. Such identity allows her to claim more decision-making power in the diversity policy of the hospital, and to achieve a higher status within her community and Belgian society at large.

\section{Aisha, Administrative Glerk at Saint Mary's Hospital}

I work at the invoicing unit. I correct invoices that we get back from the public health insurance ... I correct them and send them back. I work full time and I've been here for three years now ... I like my job.

I started half time in the patient transport unit. After my studies in administration, I didn't have a job and needed money . . B But I wanted to work full time. Then they [the invoicing unit] were looking for somebody temporary, and I took the job. And then my boss made a permanent job of it, I asked to stay and was hired. 
I had an interview with him. He had seen me work and asked me how things were going. For my first job I had to pass some tests. For the second only the interview ... Our boss is very open, he's not the typical boss. I like him ... If there are problems, he talks with us....

The cleaning staff is generally not so friendly. I don't know if it's towards all migrants or only me. When I got transferred, I had a problem with them, when I passed ... I spoke to the head of cleaning. She said that I was completely in my right and that she would talk to them: 'You're a migrant girl working in the administration, and they resent that you might feel superior to them'. While it's actually not like that. I don't have to justify myself, do I have to go around with a board 'I have a degree, this is my place, I deserve this place'? Sometimes I think that they found it strange that I got that job. It didn't use to be like that, a migrant girl in the administration. Perhaps it's because it had never happened before... I think that in the beginning [as a migrant] you have to demonstrate more ...

We often talk about differences, holidays ... During Ramadan, my colleagues avoid talking about food when I'm around . . . They don't have to, but I appreciate it. My boss also knows that I'm not at my best . . I I don't give him any problems, but still . . .

[About translating for patients who do not speak Dutch] If the doctor wants detailed information about where it hurts, how the woman feels or people want to be reassured before an operation ... It can last a while ... sometimes an hour. But I don't have deadlines in my work, so it's OK. And they ask me to do it. It's nice, a break, something completely different. But if they get angry, of if they don't agree with what I say ... I try to make the translation softer ... You can't translate literally . . like: 'you don't know anything or you're a bad doctor ...' I try to ... use a bit of tact.

You have to take off the headscarf when you enter the hospital, for hygienic reasons. I understand that, it's so difficult to get work if you refuse ... Practically impossible because most companies ask for it when you apply ...

I don't thing it's right, specific needs or so ... I I expect to be like everybody else. In some factories, when they have to do overhours on Friday afternoon, they [Muslim workers] can leave. But we don't have to pray at specific times ... You have to pray five times a day, but if you work, it's perfectly possible to do all the praying in the evening.

There is an anti-discrimination clause in the hospital bylaws. You can be fired right away for discrimination or racist comments. It's important that people know that it's not tolerated ... I really think they would take action.

I went to a school to talk about myself and my work here, how I got it. Then they [ethnic minority students] can ask questions: if it's nice, if I feel that I'm treated differently, if there are vacancies ... They will soon have to look for a job. They ask what they have to pay attention to. I think they ask themselves if they'll get a job, as migrants. The recruiter has to be open, he has to trust you. Most of the time migrants are not invited [for an interview], they see the name ... If you are, you have a chance.

I think that young people are more optimistic . . They do hire more migrants . . It gives hope...

Throughout the interview, Aisha mentions a number of material control mechanisms: her need to work to earn some money, the difficulty to find a full-time job in line with her 
qualifications, the hostility of the cleaning staff towards her, discriminatory recruitment practices (which however she did not experience personally), the hospital's expectation that she interrupts her work to translate for patients, the hospital working hours during Ramadan, migrant patients' behaviour towards doctors making translation work difficult, and the prohibition to wear the headscarf in most Belgian companies. At the same time, her professional life is affected by the hospital's identity-regulating discourse of minority employees' specific culture-related competences and the negative discourses on Moroccans in society at large.

Aisha reflects on her constraints and possibilities in each situation and attempts to act in ways that make the best out of them. For instance, in the beginning of her professional career, aware of her weak position as a fresh-out-of-school migrant, and in financial need, she chooses to take a part-time job for which she is overqualified. To meet the hospital's expectations, she also gladly consents to translate for cultural minority patients, as she feels this specific task does not interfere too much with her work at the invoice unit. She further endorses the hospital's policy forbidding the headscarf, which she considers 'normal' in Belgian organizations (and which does not affect her personally, as she does not wear the scarf), and works regularly during Ramadan. Yet, Aisha does not always comply with material controls exerted over her. For instance, she takes action to stop the disrespectful, hostile behaviour of the cleaning staff by directly addressing their superior. Doing so, she also challenges the stereotypical discourse of migrants as uneducated people, which she assumes lies at the base of the hostility towards her.

Aisha explicitly condemns discriminatory practices and the related stereotypical discourses about migrants but does so in a particularly nuanced way. For instance, she qualifies Belgians' negative attitudes towards migrants as a possible effect of the past, acknowledges the openness and support of (majority) superiors such as her boss and the head of cleaning, appreciates the tactful behaviour of her colleagues, trusts that the hospital would take action against discrimination and racism, and points to the positive evolution of the position of migrants on the labour market. At the same time, she refuses any kind of special treatment for cultural minorities. For instance, she criticizes allowing Muslims to leave earlier on Fridays, arguing that they are not required to pray at specific times. Similar to Saida, she constructs Islam as a moderate religion compatible with Belgian society.

Throughout the interview, Aisha constructs herself as an agent of her own life. Although she always acknowledges the material and discursive structure she is embedded in, she constantly reflects on situations and takes action when she feels she should. For instance, she takes the step of applying for the temporary job in the invoicing unit, for which she is qualified, and later asks her boss to stay, when the position becomes permanent. As mentioned before, she complains to the head of cleaning about the cleaning staff's hostile behaviour towards her. Finally, she shares her professional experience with minority youth who soon will face the difficult Belgian labour market. This is an indicator that she believes she can make a difference not only in her own life but also for other migrants as well.

Aisha's stress on her own power at the hospital and in her life gives her interview a rather positive tone. Unlike Saida, she does not perceive the general policies of the hospital as particularly constraining to her as a minority employee, nor does she con- 
struct a professional identity that is closely related to her cultural background. This is well indicated by the fact that she considers translating for minority patients an additional task, a break from her real job, and might also be due to the fact that the hospital's identity-regulating discourse of minority employees as cultural experts is centred around health care. Aisha builds her identity on her competences and qualifications, independently from her cultural/religious specificity, which is highlighted only when it causes unfair discriminatory treatment. Coherently with such perspective on herself, she expects to be treated fairly and as an equal both within the work environment and Belgian society at large. Aisha clearly chooses to conform to Belgian society, and develops an own strategy of micro-emancipation drawing on her competence and claiming the same treatment as majority individuals.

\section{Conclusion}

The analysis of these four accounts indicates that our interviewees engage with the constellations of controls exerted over them in different, more or less compliant ways, achieving different degrees of micro-emancipation. Ahmed complies most thoroughly, Aisha and Saida develop more nuanced identities and behaviours, and Robert resists controls the most. Ahmed's case well illustrates how compliance allows him to develop a positive identity, a stronger position on the labour market, and the power to negotiate better work arrangements. In contrast, Robert only minimally complies with organizational controls and turns to an alternative discourse to build an antagonistic identity. The two stories of Aisha and Saida illustrate more nuanced forms of compliance and resistance, attempting to make the best out of the hospital's various controls.

\section{DISGUSSION AND GONGLUSION}

This study aimed at providing a deeper understanding of how minority employees are controlled in organizations. To develop this contribution, we discuss first how organizations never control minority employees solely through managerial discourses (of diversity) but always through a constellation of both identity-regulating discourses and bureaucratic controls, and second how minority employees, as agents, actively engage with both forms of control. We then draw three key theoretical lessons for the critical literature on control and micro-emancipation, and conclude with the limitations of our study.

First, contrary to diversity studies that conflate control with discursive control, our study shows that organizations manage minority employees through constellations of discursive and material controls. The comparative analysis of the material and discursive structures and constellations of controls in the two organizations reveals two different types of approaches to managing minority employees. At TechnoLine, minority employees are managed through the company's general control mechanisms. They are expected to be and behave like a 'model employee' and are disadvantaged in as far as their difference affects their ability to meet these standard expectations. At Saint Mary's Hospital, on the contrary, minority employees are managed through a combination of general and group-specific bureaucratic and discursive controls. They are expected to be 
and behave like their majority colleagues but also as members of a cultural minority. They are disadvantaged in as far as they have to meet two sets of expectations at once, and are therefore 'doubly' managed.

The analysis of the constellations of controls at TechnoLine and Saint Mary's Hospital further indicates that an organization's material and discursive controls can be related in different ways, with rather different consequences for minority employees. At TechnoLine, we see that the material and the discursive structures and the related bureaucratic and discursive controls largely overlap, mutually reinforcing each other. The material project structure and meritocratic human resource management are dependent for their functioning on employees' adherence to the identity-regulating discourse of employees as competent, entrepreneurial, client-oriented professionals. Conversely, this latter discourse is dependent on the former material structure for its effectiveness in regulating employees' identities. Because of the coherence of the material and discursive structures, we speculate that, in this case, the possibility of micro-emancipation might be more narrowly defined. The relative lack of nuance in the opposed stories of Ahmed and Robert suggests that an individual either clearly fits in the organization and gains from it, or does not, and loses. While we do not exclude that other employees might have more nuanced accounts, there are indications that this type of context might lead to relatively more extreme cases.

At Saint Mary's Hospital, the material and discursive structure and respective controls are related in a different way. The discursive structure stressing the natural, culturesensitive family approach to care seems to operate as a compensatory mechanism, 'softening' the rigid hierarchical material structure. This is reflected in the accounts of Saida and Aisha, which are more nuanced and construct clearly distinct ways to microemancipate oneself within the organization. While we do not exclude the possibility of fully compliant or fully antagonistic identities and behaviours, we would expect a broader variety of ways to comply, resist, and emancipate oneself within such a constellation of controls.

Second, against overly deterministic and coherent accounts of managerial control of minority employees in previous critical diversity studies, our in-depth analysis of four accounts illustrates that individuals are always controlled in partially unique ways. This is because (i) an individual is subject to a unique mix of multiple controls which originate both within and outside the organization and (ii), as an agent, he or she reflects and acts upon those controls in a unique way.

The stories of Ahmed and Robert clearly illustrate how the same material and discursive structures and related constellation of controls can lead to diametrically opposite identities and behaviours. For Ahmed, the company's meritocratic human resource management system and client-oriented project structure open up possibilities for micro-emancipation which he never experienced before. He complies because this allows him to build an empowering professional identity, earn more money, increase his status in Belgian society, counter stereotypes about cultural minorities, and negotiate work arrangements that suit him. Robert's physical disability, on the other hand, precludes his micro-emancipation through his work at TechnoLine. He resorts to a resistant identity and behaviour, which better correspond to his personal position and experience. 
The comparison of Saida's and Aisha's stories also illustrates how the same constellation of controls affects individuals different ways. Saida develops a strong professional identity as a Moroccan-Muslim midwife by appropriating the hospital's diversity discourse, the hospital discourse of person-centred care in line with her professional identity as a midwife, and the Muslim-Moroccan discourse of midwifery as a suitable and respectable job for women. Aisha rather constructs an identity based on her education and competence and thus her entitlement to her job, stressing much less her specific profession as a clerk and her cultural/religious background. The comparison further indicates that agents reflect on and act upon the same controls in different ways because they have previously developed different types of subjectivities. From Saida's story, it seems that her identity was firmly anchored within her cultural minority community prior to entering the hospital, while Aisha constructs herself more as a member of Belgian society as a whole. Coherently with their different visions over themselves, Saida claims more power by virtue of her difference, Aisha claims equality and respect by virtue of her sameness.

Third, our four in-depth accounts of how the material and the discursive intersect at the subject's level to control and how in turn, individuals engage with these controls also contribute to the empirical critical literature on control. From the interpretation of these accounts, we draw three theoretical lessons for critical management studies concerning: (i) why identity-regulating discourses might be appealing to employees; (ii) the need to integrate bureaucratic control, next to identity regulation, in analyses of control and micro-emancipation; and (iii) the need to use multiple contexts of reference in analyses of control and micro-emancipation.

On the first point, our findings indicate that individuals draw on managerially inspired discourses in as far as such discourses allow them to construct a positive identity. While much critical management literature stresses individuals' need to develop a sense of belonging and security (Collinson, 2003; Knights and Willmott, 1989; Sveningsson and Alvesson, 2003), the four identities we analysed did not appear to be particularly secure. As our interviewees drew from a variety of (even conflicting) identity-regulatory discourses present in the organization and in other societal contexts to develop their identities, tensions and ambiguity remained in their accounts. What is common to our stories, instead, is that all interviewees appropriated discourses in which they could build positive identities. Developing a positive identity (or more than one) might be particularly difficult for minority employees, whose cultural, religious, disability, gender, age etc differences become often salient and meaningful in negative ways.

On the second point, our individual analyses indicate that forms of microemancipation emerge (or do not) through an individual's engagement not only with discursive controls but also bureaucratic ones. For instance, Ahmed's success in changing his working hours in a radical way during Ramadan, without prior negotiation, is exemplary of how constructing a desirable professional identity and complying with specific material controls might allow an individual not only to construct an empowering identity, but even to circumvent consolidated bureaucratic controls reflecting longstanding power relations. This finding is important because it indicates that an individual strategy might, in the long term, contribute to calling into question a bureaucratic 
control and the underlying material structure, potentially leading to change that goes well beyond one's individual micro-emancipation.

On the third point, the analysis of our empirical material suggests the need to consider multiple contexts when investigating compliance, resistance, and micro-emancipation. While micro-emancipation has to date primarily been addressed in the organizational context, our interviews indicate that minority employees are subject to various controls originating both inside and outside the organization (in school, their cultural/religious community, the city or region, their families, and their neighbourhood). What represents compliance in one of these contexts might represent micro-emancipation in another. This is clearly the case of Ahmed, who fully complies with the organization's constellation of controls, emancipating himself from his stigmatized position as an uneducated school drop-out and an unemployed migrant. The story of Saida also suggests that compliance with the hospital's bureaucratic rules and the appropriation of its diversity discourse give might possibly increase one's status in one's own community of origin. Therefore, it is not only that micro-emancipation is fragmentary and temporary, and always comes with a price, as argued by Alvesson and Willmott (1992, 2002), but also that one and the same identity and behaviour might be compliant in one context and emancipatory in another.

Such a point also has important methodological implications. To fully understand the agent's perspective, further research might want to adopt a methodology that includes in the analysis other, non-organizational contexts relevant to the subject. For instance, data on the position of specific demographic groups on the labour market, discourses on migrant and the disabled in the media, etc could be used to further develop our analysis. In a thoroughly agentic perspective, interviewees' own references to non-organizational contexts can be used as a criterion for broadening the data collection and analysis. However, other options remain available. For instance, whenever another societal context appears to play a major role in an interviewee's professional identity, the researcher might consider redesigning the research to fully account for it. For instance, he or she might take additional interviews with key people in that context, such as family members, close friends, state agency personnel, etc. In sum, as agents, in constructing their identity, make links across their different spheres of life, taking a fully agentic perspective might lead to abandoning the organization as the a priori focal setting of the analysis in favour of a more comprehensive analysis centred on the subject.

To conclude, our study also presents some major limitations. First, our interpretation carries the risk of conveying an understanding of agency that overemphasizes subjects' strategic rationality and coherence. While we have taken distance from such an understanding of the subject in the theoretical section, the methodological choice to analyse individual accounts is conducive to highlighting some degree of rationality in our informants' narratives. In the interviews, individuals narrated their experience in a way that made sense for both themselves and us at that moment (cf. Riessman, 1993). As main character of his or her own life, the interviewee emphasized his or her own role in shaping it, overshadowing the aspects he or she dislikes, does not understand, or thought might be negative in the interviewer's eyes. A similar process of erasure occurred subsequently, when we engaged with the data, selecting and interpreting the interviews which best portray the phenomenon under investigation. As scholars, we tend to privi- 
lege stories we can make sense of, allowing identification of patterns in individuals' reflections and actions, keeping ambiguity, serendipity, and contradiction as manageable as possible. Aware of the risk of representing the agent as too coherent and rational, we have attempted to interpret individual accounts in nuanced ways.

A second major limitation of our study is that our interviews allowed us to take only 'snapshots' of minority employees' identities. We could not look at how that identity evolves in time, nor do we want to suggest that it remains fixed. Finally, we have mainly focused on professional identities developed in organizational contexts. As mentioned above, this might be a plausible choice for organizational scholars, but might not do full justice to our interviewees, for whom other identities might be more important. We do not intend to claim that the identity we reconstructed in our analysis is their only or main identity. We do however believe that our interview material well represents the professional identity they had developed within their work environment at the time of the study.

\section{NOTE}

*The authors would like to thank Gerlinde Doyen and Miet Lamberts (Higher Institute of Labour Studies of the Katholieke Universiteit Leuven), Yvonne Benschop, Arie de Ruijter, Renaat Devisch, Luc Sels, and the three anonymous reviewers for their valuable inputs to the study.

\section{REFERENGES}

Alvesson, M. and Willmott, H. (1992). 'On the idea of emancipation in management and organization studies'. Academy of Management Review, 17, 432-64.

Alvesson, M. and Willmott, H. (1996). Making Sense of Management: A Critical Introduction. London: Sage.

Alvesson, M. and Willmott, H. (2002). 'Identity regulation as organizational control: producing the appropriate individual'. Fournal of Management Studies, 39, 619-44.

Bourdieu, P. (1990). The Logic of Practice. Cambridge: Polity Press.

Braverman, H. (1974). Labor and Monopoly Capital. New York: Monthly Review Press.

Collinson, D. L. (1992). Managing the Shopfloor. Berlin: De Gruyter.

Collinson, D. L. (2000). 'Strategies of resistance: power, knowledge and subjectivity in the workplace'. In Grint, K. (Ed.), Work and Society: A Reader. Cambridge: Polity Press.

Collinson, D. L. (2003). 'Identities and insecurities: selves at work'. Organization, 10, 527-47.

Dandeker, C. and Mason, D. (2001). 'The British armed services and the participation of minority ethnic communities: from equal opportunities to diversity?'. The Sociological Review, 49, 219-33.

de los Reyes, P. (2000). 'Diversity at work: paradoxes, possibilities and problems in the Swedish discourse on diversity'. Economic and Industrial Democracy, 21, 253-66.

Dickens, L. (1994). 'The business case for women's equality: is the carrot better than the stick?'. Employee Relations, 16, 5-18.

Du Gay, P. (1996). Consumption and Identity at Work. London: Sage.

Du Gay, P. and Salaman, G. (1992). 'The cult[ure] of the customer'. Fournal of Management Studies, 29, 615-33.

Eisenhardt, K. M. (1989). 'Building theories from case study research'. Academy of Management Review, 14, 488-511.

Fairclough, N. (1998). Discourse and Social Change. Cambridge: Polity Press.

Giddens, A. (1982). Profiles of Critiques in Social Theory. London: Macmillan.

Giddens, A. (1984). The Constitution of Society: Outline of the Theory of Structuration. Cambridge: Polity.

Hagedorn-Rasmussen, P. and Kamp, A. (2002). Contextualising a Decontextualised Concept of Managing Diversity. Paper presented at the international conference, 'Meeting Ourselves and Others: Perspectives in Diversity Research and Diversity Practices', Gothenburg, 29-31 August.

Jermier, J., Knights, D. and Nord, W. (Eds) (1994). Resistance and Power in Organizations. London: Routledge. 
Jones, D., Pringle, J. and Shepherd, D. (2000). 'Managing diversity meets Aotearoa/New Zealand'. Personnel Review, 29, 364-80.

Kärreman, D. and Alvesson, M. (2001). 'Making newsmakers: conversational identity at work'. Organization Studies, 22, 59-89.

Kelly, E. and Dobbin, F. (1998). 'How affirmative action became diversity management'. American Behavioral Scientist, 41, 960-84.

Kirby, E. and Harter, L. (2001). 'Discourses of diversity and the quality of work life: the character and costs of the managerial metaphor'. Management Communication Quarterly, 15, 121-7.

Knights, D. and Willmott, H. (1989). 'Power and subjectivity at work: from degradation to subjugation in social relations'. Sociology, 23, 535-58.

Kondo, D. (1990). Crafting Selves: Power, Gender and Discourses of Identity in a Fapanese Workplace. Chicago, IL: Chicago University Press.

Kunda, G. (1992). Engineering Culture: Control and Commitment in a High-Tech Corporation. Philadelphia, PA: Temple University Press.

Liff, S. (1996). 'Two routes to managing diversity: individual differences or social group characteristics'. Employee Relations, 19, 11-26.

Liff, S. and Wajcman, J. (1996). " "Sameness" and "difference" revisited: which way forward for equal opportunity initiatives?'. Fournal of Management Studies, 33, 79-94.

Litvin, D. (1997). 'The discourse of diversity: from biology to management'. Organization, 4, 187-209.

Litvin, D. (2002). 'The business case for diversity and the "iron cage"'. In Czarniawska, B. and Höpfl, H. (Eds), Casting the Other: The Production and Maintenance of Inequalities in Work Organizations. London: Routledge.

Martin, J. (1992). The Culture of Organizations: Three Perspectives. New York: Oxford University Press.

Martinsson, L. (2002). Toward a Disharmonic Pluralism: Discourse Analysis of Official Discourses About Social Diversity. Paper presented at the international conference, 'Meeting Ourselves and Others: Perspectives in Diversity Research and Diversity Practices', Gothenburg, 29-31 August.

Maxwell, G. A., Blair, S. and McDougall, M. (2001). 'Edging towards managing diversity in practice'. Employee Relations, 23, 468-82.

McDougall, M. (1996). 'Equal opportunities versus managing diversity: another challenge for public sector management?'. International Fournal of Public Sector Management, 5, 62-72.

Newton, T. (1998). 'Theorizing subjectivity in organizations: the failure of Foucauldian studies?'. Organization Studies, 19, 415-47.

Phillips, N. and Hardy, C. (2002). Discourse Analysis: Investigating Processes of Social Construction. London: Sage.

Prasad, P. and Prasad, A. (2000). 'Stretching the iron cage: the constitution and implications of routine workplace resistance'. Organization Science, 11, 387-403.

Putnam, L. and Cooren, F. (2004). 'Alternative perspectives on the role of text and agency in constituting organizations'. Organization, 11, 323-33.

Reed, M. (2000). 'The limits of discourse analysis in organizational analysis'. Organization, 7, 524-30.

Riessman, C. (1993). Narrative Analysis. Newbury Park, CA: Sage.

Roosevelt Thomas, R. (1992). Beyond Race and Gender: Unleashing the Power of Your Total Workforce by Managing Diversity. New York: AMACOM.

Sveningsson, S. and Alvesson, M. (2003). 'Managing managerial identities: organizational fragmentation, discourse and identity struggle'. Human Relations, 56, 1163-93.

Thompson, P. and Ackroyd, S. (1995). 'All quiet on the workplace front? A critique of recent trends in British Industrial Sociology'. Sociology, 29, 615-33.

Wetherell, M. and Potter, J. (1992). Mapping the Language of Racism: Discourse and the Legitimation of Exploitation. Hemel Hempstead: Harvester Wheatsheaf.

Wilson, E. and Iles, P. (1999). 'Managing diversity - an employment and service delivery challenge'. International Fournal of Public Sector Management, 12, 27-48.

Yin, R. K. (1989). Case Study Research: Design and Methods. Newbury Park, CA: Sage.

Zanoni, P. and Janssens, M. (2004). 'Deconstructing difference: the rhetorics of HR managers' diversity discourses'. Organization Studies, 25, 55-74. 